\title{
Correction to: Assessing the integration of solar power projects: SWOT-based AHP-F-TOPSIS case study of Turkey
}

\author{
Muhammad Khalid Anser ${ }^{1} \cdot$ Muhammad Mohsin $^{2} \cdot$ Qaiser Abbas $^{3} \cdot$ Imran Sharif Chaudhry $^{4}$ \\ Published online: 14 September 2020 \\ (C) Springer-Verlag GmbH Germany, part of Springer Nature 2020
}

Correction to: Environmental Science and Pollution Research (2020) 27:31737-31749 https://doi.org/10.1007/s11356-020-09092-6

The correct affiliation of the 1st Author is shown in this paper.

Publisher's note Springer Nature remains neutral with regard to jurisdictional claims in published maps and institutional affiliations.

The online version of the original article can be found at https://doi.org/ 10.1007/s11356-020-09092-6

Muhammad Mohsin

m.mohsin3801@yahoo.com

Muhammad Khalid Anser

mkhalidrao@xauat.edu.cn

Qaiser Abbas

Qabbas@gudgk.edu.pk

Imran Sharif Chaudhry

imran@bzu.edu.pk

1 School of Public Administration, Xi'an University of Architecture and Technology, Xi'an, China

2 School of Finance and Economics, Jiangsu University, Zhenjiang 212013, China

3 Department of Economics, Ghazi University, D.G Khan, Punjab, Pakistan

4 School of Economics, Bahauddin Zakriya University, Multan, Punjab 60800, Pakistan 